\title{
SUPRESSÃO DE MATA ATLÂNTICA E O PLANO DE RECUPERAÇÃO DE MATA NA REGIÃO METROPOLITANA DA BAIXADA SANTISTA
}

\author{
Renata Soares Bonavides ${ }^{1}$ \\ Kleber Lotfi ${ }^{2}$
}

\section{RESUMO:}

O Bioma Mata Atlântica é considerado patrimônio nacional, nos termos da Lei $\mathrm{n}^{\circ} 11.428$, de 2006. Sua conservação, proteção, uso e regeneração são iniciativas fundamentais para preencher os requisitos legais e fazer com que a proteção local seja possível de acordo com as normas vigentes relacionadas ao meio ambiente, em especial, o atual Código Florestal Brasileiro, Lei 12.651, de 2012. O trabalho tem como objetivo essa ocorrência na Região Metropolitana da Baixada Santista formada por 9 municípios, que se encontram sob forte intervenção antrópica. O método empregado é o hipotético-dedutivo e a metodologia documental e bibliográfica.

Palavras-chave: Mata Atlântica; conservação; RMBS; IN Ibama 09/2019; procedimentos administrativos

\section{ATLANTIC BIOME SUPPRESSION AND THE RECOVERY PLAN IN THE METROPOLITAN REGION OF BAIXADA SANTISTA}

\begin{abstract}
:
This paper is to comment about the Bioma Mata Atlântica and its conservation in the Baixada Metropolitana da Baixada Santista. It is considered a national patrimony, under the terms of Law No. 11,428 of 2006. Its conservation, protection, use and regeneration are fundamental initiatives to fulfill the legal requirements and make local protection possible according to the current norms related to the environment, in particular the current Brazilian Forest Code, Law 12.651, of 2012. The method used is the hypothetico-deductive and the documentary and bibliographic methodology.
\end{abstract}

Keywords: Atlantic Forest; conservation; RMBS; IN Ibama 09/2019; administrative procedures

\section{INTRODUÇÃO}

A pesquisa objetiva-se demonstrar a importância do plano de recuperação de Mata Atlântica na Região Metropolitana da Baixada Santista tendo em vista o desmatamento gerado pela

\footnotetext{
* Professora do Curso de pós-graduação stricto sensu em Direito Ambiental Internacional da Unisantos. Doutora e Mestre em Direito. Diretora da Graduação e da Pós-graduação da Unisantos. End. Av. Conselheiro Nébias, 589/595 - Santos/SP. Email: renatasbonavides@gmail.com

** Mestrando em Direito Ambiental pela Universidade Católica de Santos. Graduado em Direito. Advogado em Santos. End. Av. Conselheiro Nébias, 589/595 - Santos/SP. Email:
} 
ação antrópica e ainda por motivos diversos. A Mata Atlântica e seu ecossistema é o bioma que possui maior grau de supressão entre os seis existentes no Brasil e ao mesmo tempo é considerado o que possui maior biodiversidade em termos de flora e fauna.

O objetivo fundamental deste artigo é argumentar se as iniciativas que estão sendo tomadas para minimizar a degradação deste importante e fundamental bioma que ocupa toda a Região Metropolitana da Baixada Santista estão sendo ou não efetivas.

O bioma Mata Atlântica é considerado patrimônio nacional, nos termos do $\S 4^{\circ}$, do art. 225 da Constituição Federal de 1988. A Lei n ${ }^{\circ}$ 11.428, de 22 de dezembro de 2006, reitera ser este bioma patrimônio nacional genuíno a ser protegido para as presentes e futuras gerações. Esta norma busca garantir a utilização sustentável, se esta for realmente necessária diante das circunstâncias fáticas, já que a manutenção integral do remanescente deveria ser mantida, já que corresponde a um percentual abaixo dos dez por cento. A Mata Atlântica ocupa uma área de $1.110 .182 \mathrm{Km}^{2}$, o que corresponde a $13,04 \%$ do território nacional. À semelhança do bioma Amazônia, apresenta uma variedade de formações e engloba um diversificado conjunto de ecossistemas florestais com estrutura e composições florísticas diferenciadas. Sua conservação, utilização e regeneração são iniciativas que não podem deixar de ser tomadas para atender ao preceituado na Lei e viabilizar a proteção local. Esta também é a preocupação dos órgãos do Sisnama e das normas contidas nos diversos diplomas ambientais legais, em especial o Código Florestal atual, Lei no 12.658, de 2012.

A Instrução Normativa (IN) do Ibama nº 09/2019, publicada no Diário Oficial da União em 27/02/2019, estabelece novos critérios e procedimentos para anuência do Instituto à supressão de vegetação em áreas de Mata Atlântica. A análise dos pedidos passa a ter como foco as vedações previstas na Lei 11.428/2006 (Lei da Mata Atlântica) e as informações apresentadas pelos órgãos estaduais que conduzem os processos de licenciamento ambiental.

A legislação federal exige compensação ambiental quando o corte de vegetação é autorizado, seja por plantio ou destinação de área para preservação. Para garantir que essa determinação seja cumprida, a IN n 09/2019 dedicou um capítulo ao monitoramento das áreas em que há anuência. Por outro lado, impôs que, nas hipóteses em que a vegetação passível de anuência seja suprimida sem aprovação prévia do IBAMA, seja imposta sanção pelo órgão ambiental que, além de impor as sanções aplicáveis, deve exigir compensação ambiental equivalente a, 
no mínimo, o dobro da área desmatada com o objetivo de se reparar o dano ambiental e regularizar o empreendimento.

A manifestação técnica do órgão ambiental estadual, se necessária, deverá ser encaminhada ao Ibama por meio de formulário padrão, que relaciona todos os requisitos que a Lei da Mata Atlântica considera fundamental observar. Essa uniformização tem como objetivo assegurar a proteção ambiental necessária ao bioma e tornar mais eficiente o trâmite administrativo para obtenção da autorização.

A IN n 09/2019 também institui um sistema geoespacializado que reúne informações acerca das áreas suprimidas e de compensação em um banco de dados unificado para fins de levantamento e monitoramento das áreas protegidas.

Essa exigência reside no fato de que a autorização de corte, pelos órgãos estaduais do Sisnama, muitas vezes vai além do necessário, subtraindo desse bioma dilapidado sua preciosa vegetação e colocando em risco de extinção seus espécimes de fauna. Essa constatação foi observada pela equipe técnica do Ibama. Por este motivo convencionou-se a necessidade de autorização quando a área tenha pelo menos 50 hectares em meio rural ou 3 hectares em área urbana (exceto em edificações e loteamentos).

Aqui se questiona se a IN nº 9/2019 faz realmente diferença, uma vez que o estágio do desmatamento do bioma mata atlântica é crítico e, diante desse quadro, quais são os esforços empreendidos pela Região Metropolitana da Baixada Santista (RMBS) em prol do cumprimento das metas estabelecidas neste e em outros diplomar normativas para a possível proteção desse precioso ecossistema precioso para a biodiversidade brasileira. O método empregado nesta pesquisa é o hipotético-dedutivo e a metodologia documental e bibliográfica.

\section{1 - A defesa do ambiente}

Após a Segunda Guerra Mundial surgiu um novo movimento diante dos quadros caóticos existentes à época e necessários à defesa do ambiente. A principio houve esforços no uso ponderado de química nas mais diversas áreas, sobretudo a agrícola. Esse movimento ganhou ainda impulso sobretudo após 1962, com a publicação do livro de Rachel Carson, “A Primavera Silenciosa", que fez um alerta sobre o uso agrícola de pesticidas químicos 
sintéticos. A cientista destacou a necessidade de respeitar o ecossistema em que vivemos para proteger a saúde humana e o meio ambiente.

Seguindo esta tendência, o relatório "os limites para o crescimento", elaborado pelo grupo dos 30, em vista da observação pela tendência mundial na desconsideração do ambiente e degradação dos ecossistemas em diversas regiões do Planeta, encaminhou ao Instituto de Tecnologia de Massachusetts esse documento para que elaborassem relatório a ser remetido às autoridades responsáveis pelas Nações Unidas, a fim de alertar a Organização acerca dos rumos que poderiam levar o uso imoderado dos recursos ambientais, o que levaria a humanidade ao seu próprio aniquilamento e, sobretudo, das gerações futuras.

A busca por compatibilização entre desenvolvimento econômico e respeito ao meio ambiente ganhou ainda mais força com a implementação de ideias direcionadas a temática de um Direito Internacional Ambiental, tendo-se logo após o relatório do Clube de Roma, o chamamento das Nações Unidas (ONU) para uma Conferência Global para alertar as Nações com o objetivo de discutir o tema e apontar as diretrizes de uma nova ordem mundial,quanto ao esgotamento desacelerado dos recursos naturais,pondo em risco em escala global o meio ambiente e consequentemente a vida humana na terra.

Diante de uma visão mais ampla sobre a necessidade de se dar aos recursos naturais um papel fundamental em todas as relações recai também no fato de que o valor deles passou a ser intrínseco às espécies, ou seja, a ser também considerado em sua base genética. Santos (2003) afirma que “... A tecnociência e o capital global não estão interessados nos recursos biológicos - plantas, animais e humanos. O que conta é o seu potencial para reconstruir o mundo, porque potencial significa potência no processo de reprogramação e recombinação." ... “... tal estratégia considera que tudo o que existe ou existiu como matéria-prima a ser processada por uma tecnologia (biotecnologia) que lhe agrega valor. Portanto, a efetiva coisa que deve ser considerada na nova ordem é o que pode ser capturado da realidade e traduzido numa nova configuração. A informação genética contida na biodiversidade passou a ser o recurso natural mais importante para a economia.

Além desse ponto de vista econômico-genético, que não constitui o principal objeto deste trabalho, a humanidade encontra-se em uma verdadeira crise civilizacional, onde o respeito com o próximo e com a natureza não é mais objeto fundamental da convivência humana. A 
sociedade contemporânea pratica consumo exacerbado. O poder e a ganância prevalecem em face do bem geral. Visando reverter a verdadeira crise civilizacional em que a humanidade se encontra propôs-se o abandono do desenvolvimentismo predatório em nome de um novo paradigma, que combine os interesses econômicos com a proteção à natureza.

O conceito de Desenvolvimento Sustentável surgiu apenas na década de 1980, por obra da União Internacional da Conservação da Natureza e dos Recursos Naturais. Sua consagração deu-se em 1987, a partir do Relatório Brundtland, em que se assentou a necessidade de compatibilizar o crescimento econômico com a proteção ambiental. O conceito foi cristalizado naquele documento como o desenvolvimento que responde às necessidades do presente sem comprometer as possibilidades das gerações futuras de satisfazer suas próprias necessidades.

De acordo com FIORILLO (2017) o desenvolvimento sustentável tem por conteúdo a manutenção das bases vitais da produção e reprodução do homem e de suas atividades, garantindo igualmente uma relação satisfatória entre os homens e destes com seu ambiente, para que as futuras gerações também tenham oportunidade de desfrutar os mesmos recursos que temos hoje à nossa disposição.

Em 1992, a Cúpula Mundial sobre o Desenvolvimento Sustentável, conhecida por RIO+10, reuniu-se na cidade de Johannesburgo, na África do Sul, para dar continuidade às discussões iniciadas há trinta anos pela Conferência das Nações Unidas sobre o Desenvolvimento Humano (1972), em Estocolmo, e dez anos após a ECO-92, no Rio de Janeiro. Inúmeras foram as discussões, dentre elas, a busca por medidas para a proteção da biodiversidade e diminuição do efeito estufa. Procurou-se também estabelecer medidas para a implementação das Metas de Desenvolvimento do Milênio apresentadas pela ONU.

A Mata Atlântica não pode escapar a essa tendência protecionista dos ecossistemas florestais. Isto porque a defesa das florestas para o equilíbrio ecológico deve predominar para equilíbrios dos próprios ecossistemas associados e condicionados à situação geomorfológica várzeas. Ainda, de acordo com o Programa SINBIOTA (BIOTA/FAPESP), há considerável diversidade na fauna da região, distribuída sobretudo nas unidades de conservação que a compõem, entre elas, espécies ameaçadas de extinção, como a onça-pintada (Panthera onca), gavião-pega-macaco (Spizaetus melanoleucus), loboguará (Chrysocyon brachyurus) entre 
outras (Decreto Estadual n0 56.031 de 2010 que 6 http://www.biota.org.br/ 47 declara as espécies da fauna silvestre ameaçadas...).

\section{2- A defesa da Mata Atlântica}

A Mata Atlântica e a Zona Costeira, entre outros, são considerados patrimônio nacionais brasileiros sendo que sua utilização deve ser feita, nos termos da lei, dentro de condições que assegurem a preservação do meio ambiente, inclusive quanto ao uso dos recursos naturais, nos termos do $\S 4^{\circ}$ do art. 225 da Constituição Federal.

A proteção e a utilização do Bioma Mata Atlântica têm por objetivo geral o desenvolvimento sustentável e, por objetivos específicos, a salvaguarda da biodiversidade, da saúde humana, dos valores paisagísticos, estéticos e turísticos, do regime hídrico e da estabilidade social. A proteção e na utilização desse bioma leva em consideração os princípios da função socioambiental da propriedade, da equidade intergeracional, da prevenção, da precaução, do usuário-pagador, da transparência das informações e atos, da gestão democrática, da celeridade procedimental, da gratuidade dos serviços administrativos prestados ao pequeno produtor rural e às populações tradicionais e do respeito ao direito de propriedade.

Neste sentido Kokke Gomes (2016) sucintamente afirma que para a norma atualmente vigente ir ao encontro da função socioambiental ou ecológica da propriedade deveria considerar, para sua real eficácia, uma necessária concatenação entre outros instrumentos econômicos e institutos de proteção ambiental diferenciados em vigor no ordenamento, de modo a materializar essa função. Nesse sentido, o tratamento jurídico-ambiental da propriedade deveria estimular a preservação e recuperação do bioma. Isso não pode deixar de estabelecer o uso de ferramentas adequadas para combinar ação privada com ações aptas a salvaguardar a biodiversidade existente.

Isso quer dizer que todo e qualquer uso do solo deve considerar as normas existentes como um todos. Carlos Mangueira (2000) entende que já existem leis ambientais várias áreas a serem especialmente protegidas, em imóveis rurais por exemplo, o que é, em regra, dever do Poder Público fiscalizar, nos termos preceituados pelo art. 225 da Constituição Federal. Entre elas áreas destacam-se as de preservação permanente e as de reserva legal. Nesse sentido, a 
operacionalização do direito de propriedade deveria considerar fundamentalmente essas incidências, assim como outras restrições contidas em normas como a de proteção da mata atlântica. Nesse sentido, os proprietários, diante da instituição de espaço protegido por razões ambientais em sua propriedade, acham-se limitados na exploração econômica do imóvel, que muitas vezes jamais havia sido explorado. Nesse sentido alegam que estão impossibilitados de realizar qualquer exploração comercial madeireira no local, não se lembrando das áreas de reserva legal, das APPs e até das proibições do Código Florestal.

Na Região Metropolitana da Baixada Santista, no Estado de São Paulo foi criada em 1996, possui matas remanescentes em escala considerável para a manutenção do que resta do bioma, tal como as que estão próximas das nove cidades a ela pertencentes. Como indicado pela EMPLASA (2018) caracteriza-se pela diversidade de funções de seus nove integrantes. Possui o parque industrial de Cubatão e um considerável Complexo Portuário de Santos, o maior da América Latina. Desempenha funções de destaque em nível estadual, nos setores de Indústria e Turismo, e outras de abrangência regional, relativas aos comércios atacadista e varejista, ao atendimento à saúde, educação, transporte e sistema financeiro.

Toda região do bioma mata atlântica contou com elevados índices de degradação desde o primeiro ciclo agrário de sua história o cicli cafeeiro, sobretudo na Região do Vale do Paraíba. Sua paisagem foi transformada em espaços antrópicos, sobretudo diante da intensa exploração de seus recursos naturais e pelo espaço cedido para a cultura pecuária, expansão urbana, e mais atualmente com a cultura do eucalipto (Itani et al., 2011).

As transformações ocorridas na mata atlântica no Estado de São e particularmente na Região da Baixada Santista tiveram e têm relação direta com as mudanças socioeconômicas e culturais vividas pela região. Parte delas é resultado das políticas públicas adotadas para o desenvolvimento econômico e manejo das práticas comerciais, bem como o desenvolvimento da indústria e do comércio e da busca incessante em tranformar a localidade em um pólo industrial, o que cooperou com o desmatamento local. Atualmente se observa um padrão ou tendência de queda nas taxas de desmatamento do bioma Mata Atlântica em toda extensão brasileira. Sua recuperação são menos visíveis no Estado de São Paulo e ainda menos na Região em tela, mesmo considerando esforços da Agencia Metropolitana nesse sentido e de parcela da população consciente do fato. 
Assim, apesar do bioma ter chegado em níveis críticos de conservação e considerando o histórico de ocupação e uso da terra da região metropolitana, ainda possui diversidade biológica relevante e, como será demonstrado durante esta pesquisa, capacidade natural de regeneração de suas formações vegetacionais.

As ações destinadas ao desenvolvimento econômico devem atribuir um valor intrínseco à natureza, independente de sua vinculação com algum interesse humano específico, resguardando os interesses das gerações futuras. Ao congregar dois interesses conflitantes, exige que o desenvolvimento seja buscado de modo a realizar sempre uma concordância prática entre os interesses econômicos e o respeito ao meio ambiente das atuais e futuras gerações.

Muito pouco se fez nestes últimos anos para a melhoria da qualidade do ambiente na Região da Baixada, na opinião de Saleme e Carriço (2018). A degradação ambiental está se agravando cada vez mais e não há perspectivas em curto espaço de tempo para a sua recuperação. Lamentavelmente, o futuro não é animador para os próximos cinquenta ou cem anos, pois os problemas se agravarão caso não sejam tomadas medidas severas e eficazes.

Os autores destacam ainda que as informações referentes à população residente nos municípios atualmente integrantes da RM da Baixada Santista, segundo os dados apresentados pelos censos demográficos do Instituto Brasileiro de Geografia e Estatística (IBGE), a partir de 1950, revelam a saturação urbana em Santos, resultando no processo de migração entre este município e São Vicente. Além disso, os migrantes que chegavam, sobretudo do Nordeste, arregimentados pelas indústrias da região e pelo porto de Santos, passaram a se fixar em localizações mais afastadas nas periferias do polo regional, ou em assentamentos precários situados nos municípios centrais da região, em áreas ambientalmente protegidas e áreas de risco geológico e tecnológico.

Diante desse quadro o desenvolvimento sustentável na Região Metropolitana da Baixada Santista parece prática não muito simples de ser adotada. Seus níveis atuais de saturação devem baixar e a Agência Metropolitana deve ficar atenta para receber apoio das mais diversas instituições para instruir a todos os habitantes da região para cooperar com os movimentos em prol da sustentabilidade local.

\section{3 - Autorizações, fórmulas de preservação em áreas do bioma rurais e urbanas}

Revista de Direito Ambiental e Socioambientalismo | e-ISSN: 2525-9628 | Goiânia | v. 5 | n. 1 |

p. 20 - 35 | Jan/Jun. 2019. 
O art. 14 da Lei $n^{\circ} 11.428$, de 22 de dezembro de 2006, estabelece que a autorização para supressão da vegetação primária e secundária no estágio avançado de regeneração somente ocorrerá em caso de utilidade pública. A vegetação secundária em estágio médio de regeneração somente poderá ser suprimida nos casos de utilidade pública e interesse social. O $\S 1^{\circ}$ estabelece que a supressão de que trata o caput deste artigo dependerá de autorização do órgão ambiental estadual competente, com anuência prévia, quando couber, do órgão federal (Ibama) ou municipal de meio ambiente.

$\mathrm{O}$ art. 19 do Decreto $\mathrm{n}^{\circ}$ 6.660, de 21 de novembro de 2008 elencou os casos em que cabe a anuência do Ibama prévia à autorização de supressão prevista no art. 14 da Lei $\mathrm{n}^{\circ}$ 11.428/2006. Para normatizar sua competência legal na emissão de anuência à autorização de supressão de vegetação nativa da Mata Atlântica, o Ibama publicou a Instrução Normativa ${ }^{\circ}$ 22, de 26 de dezembro de 2014, que estabelece critérios e procedimentos para as análises das solicitações e concessões de anuências prévias, nos termos do art. 19 do Decreto $\mathrm{n}^{\circ}$ 6.660/2008. O procedimento para análise de solicitação e concessão de anuência prévia à supressão de vegetação deve ser precedida de instauração de processo a partir da solicitação do órgão ambiental licenciador competente, a ser protocolada na Superintendência do Ibama da circunscrição territorial objeto do pedido de anuência, verificação documental, análise e vistoria técnica, deferimento ou indeferimento da anuência e, ao final, comunicação ao órgão ambiental licenciador. O Ibama aceitará somente documentos encaminhados oficialmente pelo órgão competente.

A CETESB (2019) veicula a importante informação de que qualquer atividade que envolva a supressão de vegetação nativa depende de autorização prévia, seja qual for o tipo da vegetação. Não importa o estágio de desenvolvimento que se encontrem, pode ser inicial, médio, avançado ou clímax. Mesmo um simples bosqueamento como a retirada da vegetação do sub-bosque da floresta ou ainda a exploração florestal, sob regime de manejo sustentável, para retirada seletiva de exemplares comerciais a vedação é extraída pois deve ter o amaprado de autorização para a supressão desses exemplares da mata.

Os desafios para proteger a biodiversidade remanescente e os recursos naturais da Mata Atlântica e para restaurar a conectividade ecológica dos fragmentos são enormes. Significam dificuldades proporcionais ao tamanho e à importância da região. Estima-se que mais de 80\% dos remanescentes florestais do bioma estejam localizados em propriedades particulares. 
Como bem remarca Andre Guimarães (2005) é fundamental que as entidades que desejam a preservação da Mata Atlântica devem desenvolver e priorizar estratégias para o envolvimento direto do setor privado. Este é representado por grandes empresas ou mesmo por pequenos produtores rurais. Diante dos grandes esforços em prol da recuperação da cobertura florestal do bioma as ações sustentáveis em torno da região devem ser realizadas na escala que permita a recuperação de recursos naturais fundamentais da própria biodiversidade local.

Uma das estratégias mais promissoras para se efetivar a conservação e a recuperação dos recursos naturais e da biodiversidade em biomas retalhados e ameaçados como a Mata Atlântica são os Corredores de Biodiversidade.

O Brasil possui uma das legislações mais avançadas do mundo, incluindo na lei que institui o Sistema Nacional de Unidades de Conservação a categoria de "Reserva Particular do Patrimônio Natural - RPPN", segundo escólio de Andre Guimarães (2005). Ademais, possui unidades de conservação públicas, a exemplo de parques, estações ecológicas, reservas biológicas e categorias importantes. Todas geram proteção do bioma em torno de $1 \%$ de tudo o que existe no país. A criação dessas unidades, entretanto, não deve ser vista como a única estratégia para assegurar a conservação de remanescentes de biodiversidade e dos recursos naturais. Em outros países, a exemplo dos Estados Unidos e da Costa Rica se observa a ampliação de proteção desses espaços naturais em terrenos particulares por meio de programas e incentivos financeiros, econômicos ou sociais. Estes são verdadeiros mantenedores da biodiversidade, pois funcionam como mecanismos dispostos a manter o bioma em bom estado de conservação, além de fomentar iniciativas de recomposição de outros biomas.

A política urbana não deve escapar desses programas de proteção aos biomas, pois na própria Agência Metropolitana se deve discutir ações proativas em âmbito local para servirem de mecanismo que apoia sua conservação, sobretudo diante de iniciativas de obras com impacto ambiental. Por este motivo um representante do órgão do Sisnama local devem comparecer e opinar nas reuniões de governança e planejamento das regiões metropolitanas. Esse, aliás, é o que a Lei n. 13.089, de 2015, denomina governança interfederativa, compreendida como sendo ações de âmbito metropolitano que geram política regional em prol do meio ambiente local. 
O Plano Metropolitano (EMPLASA, 2018) pretende inaugurar um sistema de planejamento urbano metropolitano que se relaciona com a revisão do marco regulatório da cidade - do Plano Diretor (PDE) à Lei de Parcelamento, Uso e Ocupação do Solo (LPUOS) e aos Planos Regionais Estratégicos (PREs) - e avança na elaboração de uma estrutura de governança e fundo interfederativo, assim como em um sistema de infraestrutura de dados compartilhados entre os entes federados, para a formulação da legislação urbanística, com instrumentos e macrozoneamento em escala metropolitana, e a implementação de programas, serviços e projetos propriamente metropolitanos. Este é o escopo do PDUI - Plano de Desenvolvimento Integrado da Região Metropolitana de São Paulo.

\section{A recuperação da mata atlântica na Baixada Santista}

Nesse contexto, o Estatuto da Metrópole é norma editada com o intuito, entre outros, de formatar o contexto regional para promover a sustentabilidade dos biomas, preservar a mata, produzir desenvolvimento sustentável e viabilizar a recuperação dos ecossistemas que se perderam (2018), nas palavras de SALEME e CARRICO, que teceram considerações acerca do Estatuto da Metrópole. As diretrizes políticas e as ações previstas no PDUI deverão remeter-se e pautar-se à experiência acumulada dos processos participativos e finalidades amplamente legitimados pelo Estatuto da Cidade, no sentido de construção da cidade democrática, no caso, metropolitana. Considerando os pontos já apresentados, destaca-se que o Plano Metropolitano não é um conjunto de Planos Diretores, ele se detém aos problemas especificamente metropolitanos e estruturais, que correspondem às Funções Públicas de Interesse Comum (FPIC), assim como respeitarão a autonomia das diversas entidades federativas.

Esse envolvimento entre as nove municipalidades (2018) envolvidas é fundamental à consolidação de uma discussão compartilhada sobre os problemas metropolitanos estruturais e almeja avançar no desenvolvimento da metrópole, em diálogo interfederativo para avaliar, harmonizar e refletir em âmbito metropolitano as diretrizes estabelecidas em nível municipal. Isso conforme afirmado também pelos autores referidos.

Por conta do impacto provocado pela construção de diversas rodovias na Serra do Mar a Mata Atlântica foi prejudicada de diversas formas. O desmatamento gerado provocou seus prejuízos mais comuns, como a perda da biodiversidade, isso sem contar com o risco 
constante de deslizamentos e desabamentos decorrentes da pluviosidade constantes que existe na Região.

Em 2007, finalmente, o governo paulista decidiu tomar providências e determinou que a Secretaria da Habitação, por intermédio da Companhia de Desenvolvimento Habitacional e Urbano (CDHU), e a SMA atuassem juntas na busca de uma solução. Naquele mesmo ano foi realizado um mapeamento geológico e geotécnico das encostas da serra, que serviu de base para determinar quem poderia ficar ou deveria sair - as famílias com casa em beira de rio ou junto à estrada teriam obrigatoriamente de deixar o local.

Esse foi o primeiro passo na implantação do Programa de Recuperação Socioambiental da Serra do Mar, iniciado pelos bairros Cota. Como o próprio nome diz, o projeto tem dupla finalidade. Na área ambiental, o objetivo é procurar salvar o pouco que resta da Mata Atlântica, já que essa cobertura vegetal tem importância fundamental na regulação do clima e no abastecimento de água para os 18 milhões de habitantes da Região Metropolitana de São Paulo. Da mesma forma, a preservação das nascentes que se encontram na serra é vital para os mais de 5 milhões de pessoas que vivem na Baixada Santista e no restante da orla marítima do estado.

Trata-se, no entanto, de uma meta ambiciosa, que depende da remoção do maior número possível de famílias dos bairros Cota e de mudanças drásticas no local para as que ali permanecerem. Para essa empreitada, o Governo do Estado conta com um aporte de R\$ 600 milhões do Banco Interamericano de Desenvolvimento (BID, 2015), destinado tanto à oferta de habitação para a população de baixa renda, como à urbanização.

\footnotetext{
"A remoção está em pleno andamento, já reassentamos 2 mil famílias, que estão morando em prédios novos, e até o final do ano mais 500 terão o mesmo destino", diz o Secretário da Habitação, Lair Krähenbühl. "Depois de desocupados, os barracos são imediatamente demolidos, para evitar novas invasões", explica ele, acrescentando que para convencer as pessoas a mudar vem sendo oferecido a elas um leque de opções: "Faz parte do projeto disponibilizar uma Van para levar os moradores dos bairros Cota a conhecer moradias prontas na Região Metropolitana de São Paulo, em Cubatão, Itanhaém, Praia Grande e São Vicente”.
}

O Secretário informa ainda que, além de oferecer completa infraestrutura urbana - ruas asfaltadas, água, luz, esgoto, escolas, os novos conjuntos habitacionais, com unidades de dois e três dormitórios, são construídos segundo o desenho universal e estão equipados com 
aquecedor solar, medidores individuais de água, playground, churrasqueiras e, em alguns casos, até quadras poliesportivas e garagens subterrâneas. Segundo ele, $80 \%$ da clientela é constituída por famílias com renda mensal que não ultrapassa 5 salários mínimos.

Já as pessoas que decidiram habitar na serra, como no inicio de suas vidas, segundo Krähenbühl (2009), “...terão seu bairro urbanizado, com regularização fundiária, além de possibilidades de inclusão social e de capacitação profissional”. Representantes eleitos pela população fizeram curso de formação de agentes comunitários, em qureceberam informações sobre memória, cidadania, comunicação e promoção humana.

Para evitar novas invasões, o projeto prevê ainda a construção de uma via perimetral, que marcará os limites do parque. "Dessa forma, o trabalho da polícia ambiental na identificação dos habitantes locais será facilitado; além disso, com a regularização fundiária, os próprios moradores também atuarão como agentes de fiscalização”, diz o Secretário da Habitação.

Vale lembrar que os problemas que afetam a Mata Atlântica na serra do Mar não estão restritos à região de Cubatão. Na verdade, há impactos ao longo de toda a faixa litorânea do estado de São Paulo, desde a divisa com o Paraná até os limites com o Rio de Janeiro.

De acordo com a Secretaria do Meio Ambiente do Estado de São Paulo (2019), além dos barracos e casebres erguidos dentro da área do parque, existem estradas abertas sem autorização, casas e mesmo condomínios de luxo construídos ao lado de rios e cachoeiras. Muitos rios foram desviados para alimentar piscinas particulares entre outros atos irregulares contra o ambiente e atentatórios ao bioma. Por essa razão, além do Programa de Recuperação Socioambiental, está em andamento também o chamado Sistema de Mosaicos da Mata Atlântica, um programa do governo que abrange todos os loteamentos irregulares que provocam impacto na área delimitada pelo Parque Estadual da Serra do Mar, que se estende por 23 municípios.

Segundo Krähenbühl (2009) é importante que as prefeituras de todas as municipalidades pertencentes a Região Metropolitana da Baixada Santista se engajem na luta em prol da reconstrução do bioma, uma vez que essa possibilidade dará uma valiosa contribuição em termos de preservação do ambiente e controle de adensamento populacional sem planejamento. Em sintonia com o Governo do Estado, quatro municípios do litoral norte: Bertioga, São Sebastião, Ubatuba e Caraguatatuba firmaram convênio com a Secretaria da 
Habitação credenciando-se para o Programa Estadual de Regularização de Núcleos Habitacionais.

\section{Considerações finais}

A Mata Atlântica é bioma fundamental para o Brasil e toda integração de esforços para sua conservação devem ser buscadas. As alternativas relacionadas ao desenvolvimento de atividades agrícolas e florestais sustentáveis também devem ser ponderadas diante de seu alto grau de desmatamento e destruição. É o bioma mais prejudicado dos seis existentes no país e o que possui maior ocupação habitacional. Nesse sentido é imperativo que se viabilize tanto a preservação da natureza, como também o futuro das atividades produtivas e até mesmo a qualidade de vida humana na região.

O presente trabalho buscou demonstrar o programa implantado na Região Metropolitana da Baixada Santista, os métodos empregados na reconstituição do bioma Mata Atlântica, abordou a finalidade deste programa com a finalidade da recuperação da Mata Atlântica, apontou as providências, mudanças necessárias e sua abrangência nas ocupações irregulares em áreas de risco.

Apontou-se ainda o beneficio trazido por meio da Instrução Normativa (IN) do Ibama $\mathrm{n}^{\circ}$ 09/2019, publicada no Diário Oficial da União em 27/02/2019, que buscou, com sua publicação, não obstantes críticas de diversos setores, sobretudo argumentando sua suposta inconstitucionalidade, foi o estabelecimento de novos critérios e procedimentos para anuência do Instituto à supressão de vegetação em áreas de Mata Atlântica, tendo em vista sua intensa exploração e fragilidade.

A análise dos pedidos passa a ter como foco as vedações previstas na Lei 11.428/2006 (Lei da Mata Atlântica) e as informações apresentadas pelos órgãos estaduais que conduzem os processos de licenciamento ambiental. A legislação federal, doravante, exige compensação ambiental quando o corte de vegetação é autorizado, seja por plantio ou destinação de área para preservação.

Para a garantia dessa determinação a IN n 09/2019 dedicou capítulo específico ao monitoramento das áreas em que há anuência. Por outro lado impôs que, nas hipóteses em que a vegetação passível de anuência seja suprimida, com autorização de supressão de vegetação, 
porém sem anuência prévia do IBAMA, a possibilidade do órgão ambiental exigir, além das sanções aplicáveis, uma compensação ambiental equivalente a, no mínimo, o dobro da área desmatada.

Por outro lado existem os esforços da Baixada Santista, ou melhor, dos municípios que compõe a Região Metropolitana da Baixada Santista, que estão totalmente inseridos nesse bioma. Remarcou-se a importância da implementação do Estatuto da Metrópole,Lei n. 13.089, de 2015, em estabelecer a necessidade de implantação do Plano Diretor Urbano Integrado, PDUI, obrigatório para todas as regiões metropolitanas, com a finalidade de se criar obras sustentáveis. Com isto, a agência responsável deve fazer levantamento de áreas que necessitem mais de apoio para que a comunidade se esforce em buscar fórmulas para conter o constante desmatamento e destruição de seu frágil ecossistema.

Possivelmente a Instrução do IBAMA possa trazer benefícios para a Região Metropolitana e viabilizar a reconstituição da Mata Atlântica. O Estado de São Paulo pouco contribui com o replantio de espécies do bioma. O Estado do Espírito Santo logrou aumentar a Mata Atlântica com os esforços de diversas regiões metropolitanas e apoio do governo local.

\section{Referências bibliográficas}

CARSON, Rachel. A Primavera Silenciosa. São Paulo: Gaia, 2010. CETESB. Autorização para supressão de mata nativa. Disponível em . Acesso em 11.04.2019.

EMPLASA -Empresa Paulista de Planejamento Metropolitano. Região Metropolitana da Baixada Santista. Disponível em . Acesso em 11.04.2018.

FIORILlO, Celso Antonio Pacheco. Curso de Direito Ambiental Brasileiro. SãoPaulo: Saraiva,2017.

GOMES, Marcelo Kokke. Reserva Legal Florestal urbana e a preservação da mata Atlântida, Revista Direito Ambiental e sociedade, v. 6, n. 2, 2016 (p. 77-105).]

GUIMARÃES, Andre L. O desafio de Conservar e Recuperar a Mata Atlântica: Construindo Corredores de Biodiversidade. Disponível em < http://www.avesmarinhas.com.br/10\%20$\% 20 \mathrm{O} \% 20$ desafio $\% 20 \mathrm{de} \% 20$ conservar\%20e\%20recuperar\%20a\%20Mata\%20At1\%C3\%A2nt ca.PDF>. Acesso em 3.04.2019. 
KRAHENBUHL, Lair. Política habitacional na Baixada Santista. Disponível em . Acesso em 11.04.2019.

MANGABEIRA, Carlos O de. Função social da propriedade e proteção ao meio ambiente: notas sobre os espaços protegidos nos imóveis rurais. Brasília a. 37 n. 146 abr./jun. 2000.

MORAN, E. F., OSTROM, E. Seeing the Forest and the Trees: HumanEnvironment Interactions in Forest Ecosystems. Cambridge: MIT Press, 2005.

ITALIANI, M. R., BARROS, C. M., FOGUEIREDO, F. E. L., ANDRADE, M. R. M., MANSOR, M. T. C., MANGABEIRA, R. L., CARVALHO, V. S. Subsídios ao planejamento ambiental: Unidade de Gerenciamento de Recursos hídricos Paraíba do Sul São Paulo: Ed. SAM, 2011.

RELATORIO BRUNTDLAND. Disponível em . Acesso em 03.04.2019.

SANTOS, L. G. dos. Politizar as novas tecnologias: o impacto sócio-técnico da informação digital e genética. São Paulo: Editora 34, 2003.

SALEME, E. R. e CARRIÇO J.M. Dos planos municipais ao plano de desenvolvimento urbano integrado. Disponível em http://repositorio.ipea.gov.br/bitstream/11058/8686/1/Dos\%20Planos.pdf>. Acesso em 11.04.2019.

SINBIOTA-FAPESP. . Disponível em 02.04.2019. SIRVINSKAS, Luís Paulo. Manual de Direito Ambiental. São Paulo: Saraiva, 2018. 